\title{
Systemic analysis of the response of Aspergillus niger to ambient pH Mikael R Andersen ${ }^{\not *}$, Linda Lehmann ${ }^{\not *}$ and Jens Nielsen ${ }^{* *}$
}

\author{
Addresses: *Center for Microbial Biotechnology, Department of Systems Biology, Technical University of Denmark, DK-28oo Kgs. Lyngby, \\ Denmark. ${ }^{\dagger}$ Current address: Department of Chemical and Biological Engineering, Chalmers University of Technology, SE-412 96 Gothenburg, \\ Sweden. \\ $₫$ These authors contributed equally to this work.
}

Correspondence: Jens Nielsen. Email: nielsenj@chalmers.se

Published: I May 2009

Received: 12 February 2009

Genome Biology 2009, 10:R47 (doi:10.1 186/gb-2009-10-5-r47)

Accepted: I May 2009

The electronic version of this article is the complete one and can be found online at http://genomebiology.com/2009//0/5/R47

(c) 2009 Keilwagen et al., licensee BioMed Central Ltd.

This is an open access article distributed under the terms of the Creative Commons Attribution License (http://creativecommons.org/licenses/by/2.0), which permits unrestricted use, distribution, and reproduction in any medium, provided the original work is properly cited.

\begin{abstract}
Background: The filamentous fungus Aspergillus niger is an exceptionally efficient producer of organic acids, which is one of the reasons for its relevance to industrial processes and commercial importance. While it is known that the mechanisms regulating this production are tied to the levels of ambient $\mathrm{pH}$, the reasons and mechanisms for this are poorly understood.

Methods: To cast light on the connection between extracellular $\mathrm{pH}$ and acid production, we integrate results from two genome-based strategies: A novel method of genome-scale modeling of the response, and transcriptome analysis across three levels of $\mathrm{pH}$.

Results: With genome scale modeling with an optimization for extracellular proton-production, it was possible to reproduce the preferred $\mathrm{pH}$ levels for citrate and oxalate. Transcriptome analysis and clustering expanded upon these results and allowed the identification of 162 clusters with distinct transcription patterns across the different $\mathrm{pH}$-levels examined. New and previously described $\mathrm{pH}$-dependent cis-acting promoter elements were identified. Combining transcriptome data with genomic coordinates identified four $\mathrm{pH}$-regulated secondary metabolite gene clusters. Integration of regulatory profiles with functional genomics led to the identification of candidate genes for all steps of the pallpacC $\mathrm{pH}$ signalling pathway.

Conclusions: The combination of genome-scale modeling with comparative genomics and transcriptome analysis has provided systems-wide insights into the evolution of highly efficient acidification as well as production process applicable knowledge on the transcriptional regulation of $\mathrm{pH}$ response in the industrially important $A$. niger. It has also made clear that filamentous fungi have evolved to employ several offensive strategies for out-competing rival organisms.
\end{abstract}

\section{Background}

The subject for much discussion has been why Aspergillus niger produces organic acids in the amounts of which it is capable of. If $A$. niger is grown in an unbuffered medium, it will fairly quickly acidify the medium to a $\mathrm{pH}$ below 2 . Production processes with cultivation of $A$. niger can convert as 
much as $95 \%$ of the available carbon to organic acids, making it a viable process for producing bulk chemicals [1]. The evolutionary strategy behind this trait remains obscure, but one of several hypotheses suggests that the secretion of acids helps degrade the plant cell walls on which the saprotrophic fungus thrives, that it slows the growth of competing organisms, and that the organic acids chelate sparse trace metals and make them available to the fungus [2].

The production of organic acids by $A$. niger has been shown in several studies to be dependent on ambient $\mathrm{pH}$. Oxalic acid production is most efficient at $\mathrm{pH} 5$ to 8 and is completely absent below pH 3.0 [3]. Gluconic acid production is optimal at $\mathrm{pH} 5.5$, but it is found at all levels of $\mathrm{pH}$ from 2 through 8 $[4,5]$. Citric acid production begins at $\mathrm{pH} 3.0$ and is optimal just below pH 2.0 $[1,6]$. This suggests that an evolutionary process has selected for production of a given acid at different $\mathrm{pH}$ values. In this context, the work of Ruijter et al. [3] is interesting. They showed that a mutant strain of $A$. niger, deficient in producing gluconic acid and oxalic acid, produces citric acid at an optimum $\mathrm{pH}$ of 5 and without the demand for an $\mathrm{Mn}^{2+}$-deficient medium, which is normally essential for the production of citric acid. This suggests that the aforementioned evolution of acid production has resulted in a sophisticated system of preferred acids as a function of ambient $\mathrm{pH}$, which even ensures that another acid is produced when conditions are unfavorable for production of the preferred acid. To improve our understanding of these systemic behaviors, we have adopted a genome-scale-based strategy founded on the integration of multiple types of genome-wide data ('omics'), particularly genome-scale modeling, functional genomics, and transcriptomics.

This approach allowed us to formulate the hypothesis that $A$. niger strives to produce - at a given $\mathrm{pH}$ - the organic acid that most efficiently acidifies the medium. To test this hypothesis, the model of $A$. niger metabolism presented by Andersen et al. [7] was expanded with reactions describing the average number of protons released from one mole of a given acid at a given $\mathrm{pH}$, based on acid disassociation constants (Figure 1). This allows the use of mathematical optimization principles coupled with the knowledge of metabolic pathways, and thereby computationally determining the most efficient way of producing protons to acidify the surrounding medium as a function of $\mathrm{pH}$. If these computations are in agreement with the $\mathrm{pH}$ dependencies of the organic acids described earlier, it will be strong evidence that $A$. niger is evolutionally optimized for acidifying its environment.

The response to ambient $\mathrm{pH}$ is relevant not only in the context of organic acid production. Aspergillus niger is an expression system for both homologous and heterologous proteins, and the expression of yield-lowering proteases has been shown to be dependent on $\mathrm{pH}$ [8]. Additionally, whereas processes with $A$. niger have until now been considered safe for foodgrade enzyme production, a recent analysis of the $A$. niger

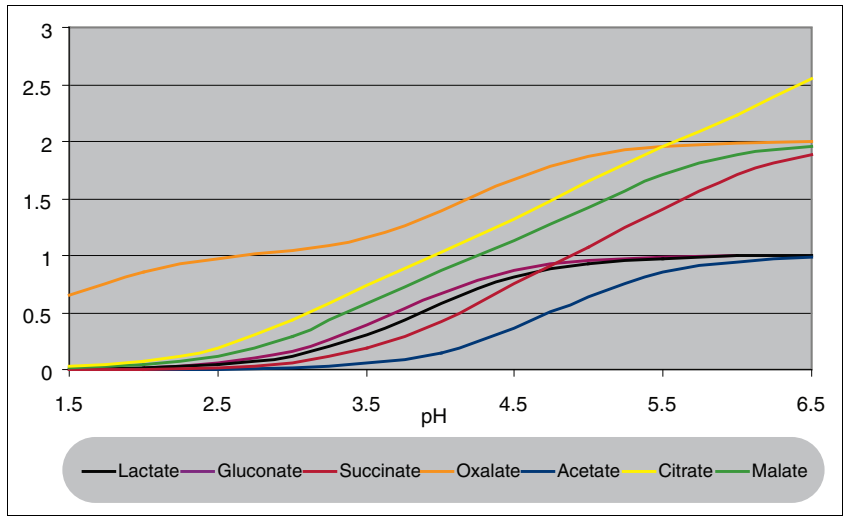

Figure 1

Protons per molecule of the original un-disassociated acid as a function of $\mathrm{pH}$.

genome [9] suggested that it may be capable of producing the carcinogenic compound fumonisin $\mathrm{B}_{2}$, which was confirmed by Frisvad et al. [10]. The carcinogen ochratoxin A has also been known to be produced by $A$. niger under certain culturing conditions $[11,12]$. Secondary metabolite production, such as penicillin from Aspergillus nidulans, has in some cases been shown to be dependent on $\mathrm{pH}$ [13]. Therefore, to expand on the results of the model-driven investigation of the organic acid response to $\mathrm{pH}$, a physiological characterization and transcriptome analysis of triplicate cultivations at $\mathrm{pH} 2.5,4.5$, and 6.0 was made to provide a systems-wide insight into the transcriptional response to ambient $\mathrm{pH}$. This allowed the identification of several genes involved in the production of organic acids reacting directly and in a coordinated manner to ambient $\mathrm{pH}$.

Given that $A$. niger can grow stably at $\mathrm{pH}$ values ranging from below 2 to above 8 [14], it is reasonable to expect sophisticated transcriptional regulation. To use this, putative $\mathrm{pH}-$ dependent cis-acting regulatory motifs were identified. With genetic engineering of promoter regions, this may be applied to induce the production of a given gene product at the $\mathrm{pH}$ of the process. Another analysis was on the production of organic acids as well as identification of secondary metabolite clusters responding to $\mathrm{pH}$. Furthermore, the $\mathrm{pacC} / \mathrm{palAB}$ $C F H I$ system, a conserved fungal signal-transduction and transcriptional-regulation system, described in detail for $A$. nidulans and partially conserved in Saccharomyces cerevisiae $[15,16]$, was examined, and likely orthologues were found and confirmed to have similar transcriptomic profiles in $A$. niger.

\section{Results}

\section{Reproducing $\mathbf{p H}$-dependent acid production in silico}

A previously described genome-scale stoichiometric model of A. niger metabolism [7] was expanded, as described in Materials and methods. Acid production was simulated from $\mathrm{pH}$ 
1.5 through 6.5 by using two different strategies: either optimization for maximal biomass production coupled to acid generation, or optimization for maximal proton generation with a fixed biomass production. The model was allowed us to use acetate, oxalate, lactate, malate, succinate, citrate, and gluconate to acidify the medium, all acids that have been observed in fermentations in our laboratory or that have been reported to be produced by $A$. niger. For each set of simulations, the acids were removed one at a time, to explore the order in which the $A$. niger simulation preferred to produce the different acids at the investigated values of $\mathrm{pH}$. For complete modeling results, see Additional data files 1 and 2.

Interestingly, if all acids are included, the simulations predict oxalate as the only produced acid throughout the spectrum of $\mathrm{pH}$. This is in agreement with the observation of Ruijter et al. [3] (and the physiological characterization in the experiments described later) that oxalate is the preferred acid in a strain capable of producing all acids.

Ruijter et al. [3] also reported that the production of oxalate peaks above $\mathrm{pH} 5.5$, and as the calculations of Figure 1 show, this is the value at which oxalate is fully disassociated, and the value of $\mathrm{pH}$ at which the effect of producing oxalate for acidifying the medium levels out. The modeling results are thus in very good agreement with the hypothesis that oxalate is produced to acidify the medium, and this explains how this trait has evolved.

One could think that because oxaloacetate hydrolase - the only enzyme producing oxalic acid in A. niger [17] - forms 1 mole of acetate for every mole of oxalate, acetate should also appear as a product in the model simulations. However, acetate formation is not seen, meaning that the simulations predict that it is more energetically efficient to remetabolize this acetate than to use it for acidification of the medium. This is in agreement with the report by Ruijter et al. [3] that $A$. niger catabolizes acetate at a rate sufficient to prevent its formation during production of oxalate.

However, this initial modeling did not predict how oxalate production diminishes drastically below $\mathrm{pH} 3$ [3] (Pedersen et al. [2] reported this limit to be below $\mathrm{pH} 4$ ), suggesting that it is due, not to inefficient acidification of the medium, but to some other factor. To simulate this, the model was adjusted to disallow medium acidification by oxalate below $\mathrm{pH} 3$ (modeling results in Figure 2).

With this model, it was found that for both modeling strategies at $\mathrm{pH}$ levels of 1.5 to 2.5 , citrate is the optimal acid for medium acidification when oxalate cannot be produced. This is the same interval used for industrial production of citric acid [1]. The necessity of the absence of oxalate production may be one reason for which very low levels of manganese are required for citrate production. Oxaloacetate hydrolase (OahA) is dependent on manganese and has a high affinity for

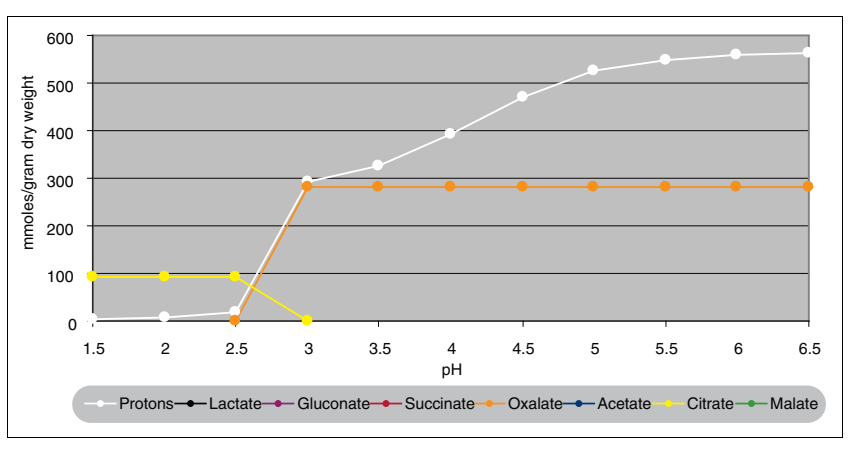

Figure 2

Simulated acid production with optimization criterion of maximal protons per gram of biomass. Acid disassociation was included in the model for all of the shown species, with the exception of oxalate production below $\mathrm{pH}$ 3.0.

the metal $\left(\mathrm{K}_{m}\right.$ for $\mathrm{Mn}^{2+}$ is $4 \mu \mathrm{M}$ [2]). Deletion of oahA in the work of Ruijter et al. [3] replicates this effect of manganese depletion, thereby inducing citrate production.

Further simulations removing proton-producing acids one by one from the model (see Additional data files 1 and 2) indicates that the $\mathrm{pH}$ interval of 1.5 to 2.5 is the only area where citrate is the most optimal acid, indicating how this $\mathrm{pH}$ preference may have evolved. Another interesting finding was that gluconate is not produced in any versions of the model unless production reactions for all other acids are removed. Because of the optimization criterion of the model, these calculations show that production of gluconate is not an energyefficient method of acidifying the medium. It therefore seems likely that the efficient conversion of glucose to gluconate by A. niger has evolved not as a way of acidifying the medium, but rather as a mechanism to make rapidly glucose unavailable to competing organisms. In this context, it is interesting to note that the gluconate production is more efficient around $\mathrm{pH}$ 5.5, a pH level at which many fast-growing bacteria have their pH optimum.

\section{Physiological studies}

To expand on the in silico predictions for organic acid production with in vivo experiments, and to gain information on other $\mathrm{pH}$-dependent aspects of fungal metabolism, batch fermentations of $A$. niger BO-1 were performed in triplicates at three different $\mathrm{pH}$ values (2.5, 4.5, and 6.0). For each fermentation, samples were taken for determination of sugar and acid concentrations. Profiles of the cultures are shown in Figure 3. Examination of Figure 3 shows that the biomass yield decreases with increasing $\mathrm{pH}$. The final biomass concentration measured decreases from $9.80 \pm 0.42 \mathrm{~g} / \mathrm{L}$ over $6.20 \pm$ $1.05 \mathrm{~g} / \mathrm{L}$ to $4.81 \pm 0.52 \mathrm{~g} / \mathrm{L}$ as $\mathrm{pH}$ increases (average \pm standard deviation). This is due to a reciprocal increase in the produced acids. Most predominant among these is gluconate production, which is not found at all at $\mathrm{pH} 2.5$, but reaches as much as $10 \mathrm{~g} / \mathrm{L}$ at $\mathrm{pH}$ 6.0. An increase in oxalate production 


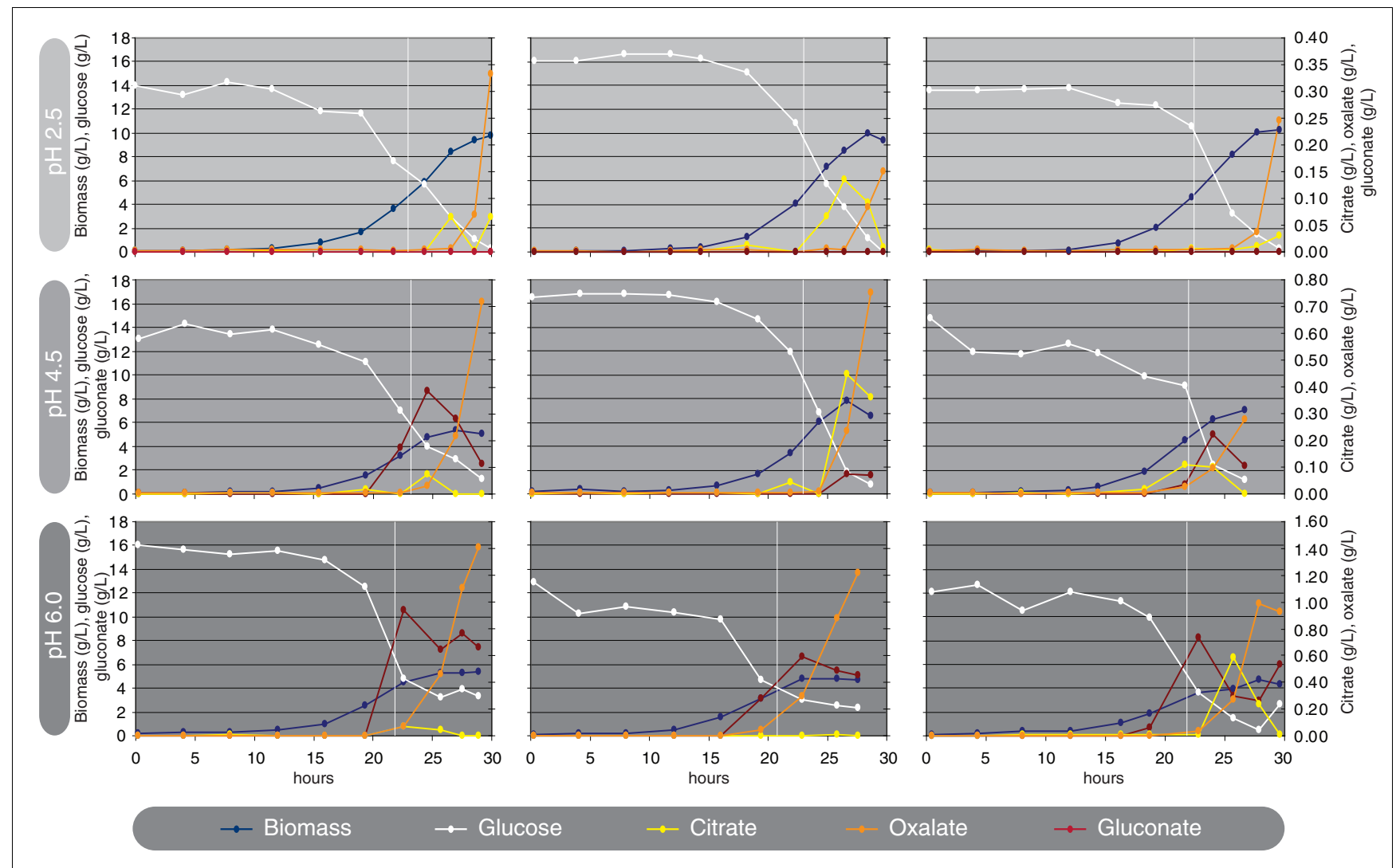

\section{Figure 3}

Metabolite profiles under cultivations of Aspergillus niger at three levels of $\mathrm{pH}$. For each $\mathrm{pH}$ value is shown three replicates, from which biomass was sampled for transcriptome analysis. Sample times are shown with white vertical lines. Note that the $\mathrm{pH}$ shown in the left column is the $\mathrm{pH}$ at the time of sampling for transcriptome analysis. All cultures were inoculated at pH 2.5 and increased at the beginning of the growth phase if needed (see Methods for details).

of roughly a factor of two also is seen with each step of $\mathrm{pH}$ increase. Finally, pH does not seem to have an effect on the citrate production in these cultivations. This is not surprising, as manganese was added to ensure reproducible filamentous growth for the transcriptome analysis. As Dai et al. [18] showed, $\mathrm{Mn}^{2+}$ concentrations of 1,00o parts per billion (ppb) (the same as in the cultivation medium) ensures filamentous growth; however, this diminishes citrate production.
Additionally, citrate production is known to be limited at glucose concentrations below 2.5\% [19]. Citrate concentrations are low in all batches, and the citrate-production profile is by far the least-reproducible trait across the triplicates.

From each of the nine fermentations, samples were taken for transcriptome analysis. Table 1 presents a summary of the growth and fermentation-broth composition at the time of sampling. As Table 1 shows, no significant acid production

Table I

Sugar, acid, and biomass concentrations for $A$. niger cultivations at three levels of $\mathrm{pH}$

\begin{tabular}{cccccccc}
\hline $\mathrm{pH}$ & $\begin{array}{c}\text { Time } \\
(\mathrm{h})\end{array}$ & $\begin{array}{c}\mu_{\max } \\
\left(\mathrm{h}^{-1}\right)\end{array}$ & $\begin{array}{c}\text { Biomass } \\
(\mathrm{g} / \mathrm{L})\end{array}$ & $\begin{array}{c}\text { Glucose } \\
(\mathrm{g} / \mathrm{L})\end{array}$ & $\begin{array}{c}\text { Citrate } \\
(\mathrm{g} / \mathrm{L})\end{array}$ & $\begin{array}{c}\text { Oxalate } \\
(\mathrm{g} / \mathrm{L})\end{array}$ & $\begin{array}{c}\text { Gluconate } \\
(\mathrm{g} / \mathrm{L})\end{array}$ \\
\hline 2.5 & $22.77 \pm 0.40$ & $0.21 \pm 0.01$ & $4.68 \pm 0.16$ & $8.93 \pm 1.84$ & $0.01 \pm 0.01$ & $0.00 \pm 0.00$ & $0.00 \pm 0.00$ \\
4.5 & $22.72 \pm 0.63$ & $0.21 \pm 0.01$ & $4.40 \pm 0.47$ & $7.87 \pm 1.97$ & $0.05 \pm 0.05$ & $0.02 \pm 0.02$ & $2.39 \pm 3.05$ \\
6.0 & $21.47 \pm 0.69$ & $0.22 \pm 0.02$ & $3.71 \pm 0.42$ & $5.24 \pm 1.21$ & $0.02 \pm 0.03$ & $0.07 \pm 0.05$ & $6.36 \pm 1.90$ \\
\hline
\end{tabular}

Biomass (dry weight), sugar, and acid concentrations for A. niger cultivations at three levels of $\mathrm{pH}$ at the time of sampling for transcriptome analysis. The calculated maximal specific growth rate is indicated. Values are shown as average \pm standard deviations for three replicates. 
(except for gluconate production) was measured in the medium at the time of the mRNA sampling. The sampling time was chosen to be in midexponential phase, as the cell is in a reproducible pseudo-steady state at this time, thus describing $\mathrm{pH}$-dependent mechanisms most reproducibly. Later sampling could result in an increased effect from extracellular acids.

\section{Transcriptome analysis}

Samples were taken from the bioreactor cultivations for transcriptome analysis. All cultures were growing as dispersed hyphal mycelium. See Table 1 and Figure 3 for details of sampling times and conditions. Data from the three biologic triplicates at pH 2.5, 4.5, and 6.0 were statistically analyzed, and genes that are significantly regulated (Benjamini-Hochberg corrected Bayesian $P$ values < 0.05) in pair-wise comparisons between two $\mathrm{pH}$ levels were identified.

A surprisingly large number of genes $(6,228)$ were identified to show significant differences in transcription levels in one or more of the comparisons. As the statistical test is a very conservative one, and more than $70 \%$ of these genes are significant in more than one comparison, this high number should not be seen as a statistical artefact, but rather as a combined effect of the wide range of $\mathrm{pH}$, a growth effect, and possible differences in medium composition at the time of sampling for transcriptome analysis.

To separate the effects and to identify genes for which the expression indices follow the level of $\mathrm{pH}$, the regulated genes were sorted into subsets according to the direction of the statistically significant responses in the pair-wise comparisons (Figure 4a). Subsets will be referred to in the text by the letter designated in Figure 4.

Especially noteworthy is the large subset $\mathrm{J}$ (2,814 genes), which is upregulated at $\mathrm{pH} 2.5$ and 6.0 compared with $\mathrm{pH} 4.5$. It is likely that this subset is not directly regulated by $\mathrm{pH}$, but rather is a part of a growth effect or a stress response, as it contains a large number of housekeeping genes, such as ribosomal subunits, DNA replication machinery, proteasome subunits, RNA-processing machinery, and so on. A GO term overrepresentation analysis (see Additional data file 3) confirmed that these terms are over-represented. The same seems to be the case for the two subsets $Q$ and N. These subsets have the same regulatory pattern as subset $J$, but with one of the statistical comparisons being statistically insignificant. Therefore, clustering the genes in this manner accord-

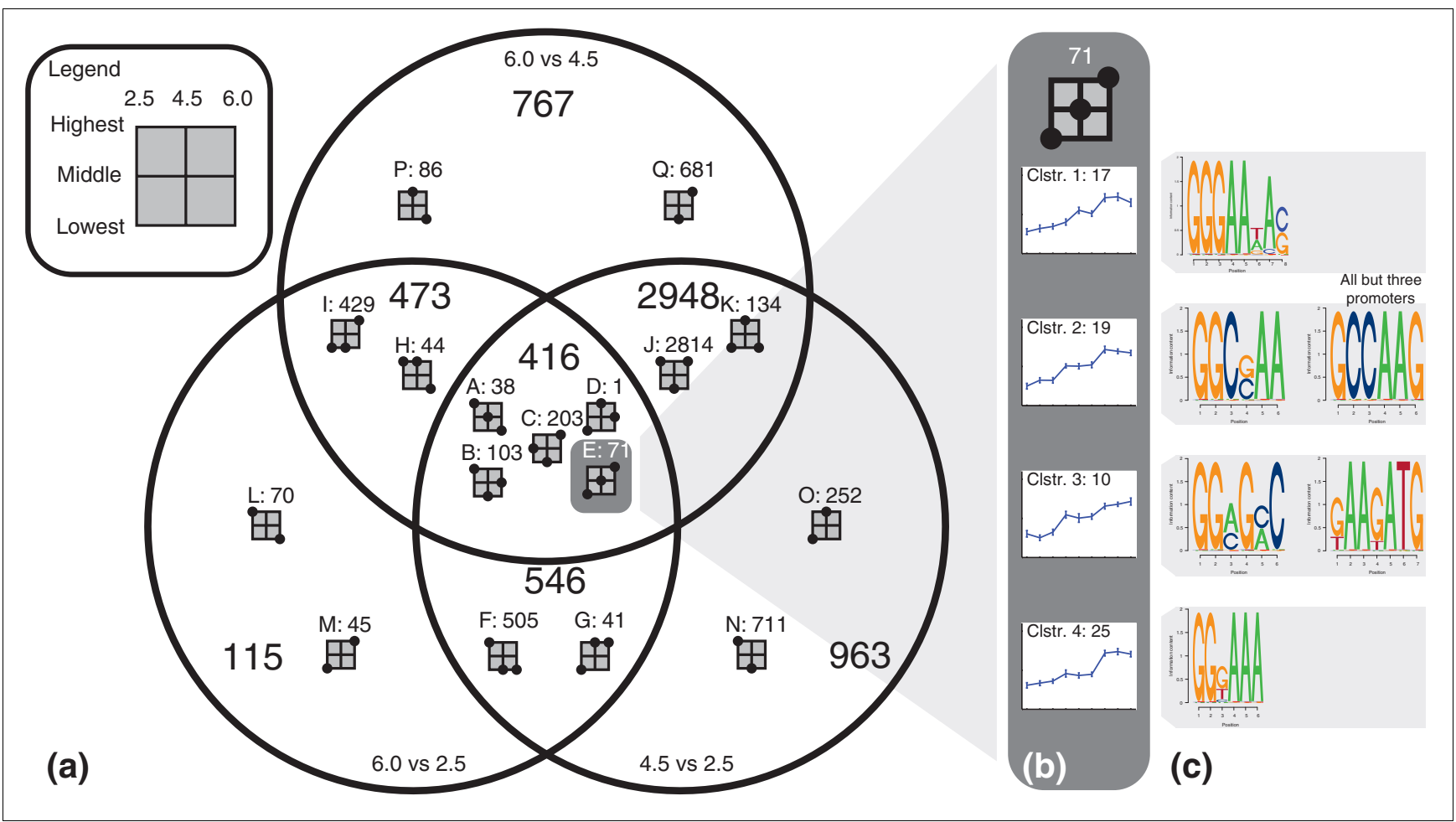

Figure 4

Venn diagram and clustering of genes with a significant transcriptional response to $\mathrm{pH}$. The Venn diagram (a) is based on three pairwise comparisons. Each area in the Venn diagram is divided into subsets by the direction of the response in the different comparisons. The formation of dots in the squares shows the general tendency of the response, with the example of (b) having expression indices increasing with $\mathrm{pH}$. Two dots on the same line means that no statistically significant difference was found between the two conditions. Each subset has been divided into clusters, as shown for the example subset (b). Predicted recognition motifs for cis-acting elements are shown (c). Sequence logos are made as described by Schneider and Stephens [63]. 
ing to the direction of the responses allows a separation of growth-related effects into subsets $\mathrm{J}, \mathrm{Q}$, and $\mathrm{N}$, thus leaving the remaining subsets (2,022 genes) with a higher likelihood of being directly influenced by $\mathrm{pH}$. Of these, the 109 genes in subsets $\mathrm{A}$ and $\mathrm{E}$ are of especially high interest, as these are following the levels of $\mathrm{pH}$ either directly (E) or inversely (A). This makes the genes in these clusters extremely likely to be regulated solely by $\mathrm{pH}$ and by none of the other varying factors of the cultivations.

Another point worth evaluating, when doing transcription analysis in batch cultures, is whether differing levels of glucose affect the results through glucose repression. Because the strategy of sampling at similar concentrations of biomass, to reflect the same ages of the cultures, the residual glucose concentration varies slightly between the cultures (Table 1). CreA-mediated carbon repression is well described in $A$. niger and known to be dependent on the concentration of the carbon source [20]. Genes affected by carbon repression would thus have a profile similar to those of subset I (429 genes). However, CreA is known to be autoregulated in $A$. nidulans [21], and CreA is not found to have significantly changed expression levels in any comparisons. This makes the presence of significant carbon regulation unlikely and, if present, restricted to the genes of subset I.

To examine patterns in transcription levels in the sets in more detail, a clustering algorithm was applied by using expression indices from all nine microarrays rather than averages for each group (Figure 4b). This method allowed more-detailed differentiation between the genes and the creation of clusters within each subset. In total, 162 clusters with distinct transcription patterns across the experiments were identified. An overview of the expression profiles of the clusters was made (see Additional data file 4), as well as details for each gene (see Additional data file 5).

Clustering of these genes facilitates discovery of interesting co-regulations. Especially interesting for the production of gluconic acid is the observation that the cellular membranebound catalase (catR) [22,23], is tightly co-regulated with the hydrogen peroxide- and gluconic acid-producing glucose oxidase (Gox/GodA; EC 1.1.3.4) [24,25]. Both are found in the same cluster of subset $\mathrm{G}$ in Figure 4. The general regulation in this subset is in good agreement with reports that oxalic acid is produced in very low amounts below pH 4.5 [4,5]. Examination of the promoter region of the genes of that particular cluster was performed to discover potential cis-acting elements, and two motifs were found, one being 5'-GAGGWT-3', and the other, 5'-ACRARAG-3'. The first motif is found 9 times in the promoter of $\operatorname{god} A$, and 5 times in the catR-promoter, making it very likely that this motif is responsible for the co-regulation of the two genes.

Another subset of special interest to acid production and regulation by ambient $\mathrm{pH}$ is subset $\mathrm{E}$. This subset contains three putative acid transporters, the oxalic acid-producing oxaloacetate hydrolase $(o a h A)[2,17]$, and the gene for a protein-regulating response from neutral to alkaline $\mathrm{pH}$ (PacC) [26]. Clustering of the genes places oahA in cluster 1 and pacC in cluster 3. In light of the lack of production of acetate, it is interesting that oahA does not seem to be co-regulated with a potential acetyl-CoA synthase or an enzyme with a similar function. This suggests that activation of acetate with CoA is not limiting for reassimilation.

As an application example of the clustering, cis-acting elements have been predicted for all four clusters of the subset containing pacC and oahA. Conserved motifs were found for each of the four clusters (Figure 4c), but not for the subset as a whole. A survey of subset A and the three subclusters (see Additional data file 4) showed that it was possible to find putative regulatory motifs for each of the subclusters, but not for the entire subset. That no common motif could be found for neither subset A or E supports the strategy of dividing the subsets into clusters to find truly co-regulated genes.

In an examination of the predicted motifs of subset $\mathrm{E}$ (Figure $4 \mathrm{c}$ ), the second motif for cluster 2 was found to be similar to the $A$. nidulans PacC consensus-binding motif 5'-GCCARG-3' reported by Sarkar et al. [27]. This suggests that members of this group are regulated at least in part by PacC. PacC is known to be autoregulated in $A$. nidulans $[28,29]$, and the motif is found in the $A$. niger pacC promoter as well. However, the clustering of pacC outside of cluster 2 suggests that other factors are regulating it, giving it a slightly different transcription profile from that of the members of cluster 2.

Expanding the examination of the co-regulated groups of genes, information was used on the physical location of the genes on the genomic scaffolds to find 147 clusters of genes on the genome that are colocalized as well as co-regulated. Manual inspection of the clusters allowed the identification of six putative gene clusters involved in secondary metabolite biosynthesis. Two of these were found in clusters J and Q, making them less likely to be directly regulated by $\mathrm{pH}$. One of the remaining four clusters is found in subset E, cluster 2, described earlier, and contains five colocalized and co-regulated genes. A putative gibberellin-precursor synthase (Gene ID 54123) is found in this cluster.

A specific study of the three potential citrate synthases identified by Pel et al. [30] showed that only one is significantly regulated in any comparison: an upregulation at $\mathrm{pH} 4.5 \mathrm{com}-$ pared with pH 2.5 (Ano8g10920/ID 176409). This does not correspond to a $\mathrm{pH}$-dependent upregulation at $\mathrm{pH} 2.5$, as would be the expected response for a citrate-synthase involved in citrate-overflow metabolism. This suggests that the $\mathrm{pH}$-responsive nature of citrate production is controlled at another level (that is, transport or post-translational regulation) or that the response requires other sensing responses (manganese [18], high glucose [19], and so on) in addition to 
acidic $\mathrm{pH}$. Based on the combined results of the modeling and the transcriptome analysis, the latter option seems to be the most likely.

Several industrially relevant proteins that are not discussed in detail here are found in the list of regulated genes, including the protease regulator PrtT, the acetate response regulator FacB/AcuB, $\alpha$-amylases, and a large number of characterized and putative glucoside hydrolases, as identified by Pel et al. [30]. A table of the 6,228 regulated genes along with information on regulation and clustering has been compiled (see Additional data file 5).

\section{Data integration-based identification of the elements of the ambient $\mathrm{pH}$ signal-transduction pathway (pal) pathway in $A$. niger}

It is known that proteolytic cleavage is required for activation of PacC in both A. nidulans [28,29,31-33] and A. niger [8]. Although the signal-transduction/proteolysis pathway in $A$. niger is, to our knowledge, uncharacterized, a two-step activation system for PacC is well described for $A$. nidulans (reviewed in references [15,34] and [16]).

The model of the pH-signaling transduction pathway in $A$. nidulans (Figure 5) consists of two distinct protein complexes, a plasma membrane-localized sensing complex (PalF, PalHI [35-41]) and an endosomal membrane complex (Pal$\mathrm{ABC}, \mathrm{Vps} 32$ [42-46]), catalyzing the first proteolytic step of PacC $[39,45]$ followed by a proteasome-catalyzed cleavage to the active form.

The pal pathway has been described as being 'mechanistically dissimilar to all other known eukaryotic signal transduction pathways' [44], and it is thus very likely that homologues of the $A$. nidulans pal genes in $A$. niger are indeed orthologues. A survey of the genome sequence of $A$. niger found homologues of all identified genes of the signaling pathway (Table 2).

The mRNA levels of the components of the pal pathway are not $\mathrm{pH}$ regulated in $A$. nidulans $[39,46]$, and an investigation of expression indices of the $A$. niger homologues indicates that these behave in the same manner. The putative $A$. niger palA and palC are not found to be significantly regulated in any comparison. palB, palH, palI, and vps32 are significantly regulated, but are found in subsets $\mathrm{J}$ and Q of Figure 4, which were found earlier to be more likely to be regulated by growth-dependent effects than by $\mathrm{pH}$. It thus seems that the A. niger homologues of the pal pathway are independent of ambient $\mathrm{pH}$ as well, but may be subject to other regulation.

\section{Discussion}

Despite the great interest in organic acid production in $A$. niger - citric and gluconic acid are bulk chemicals produced by $A$. niger processes - very little work has been published on

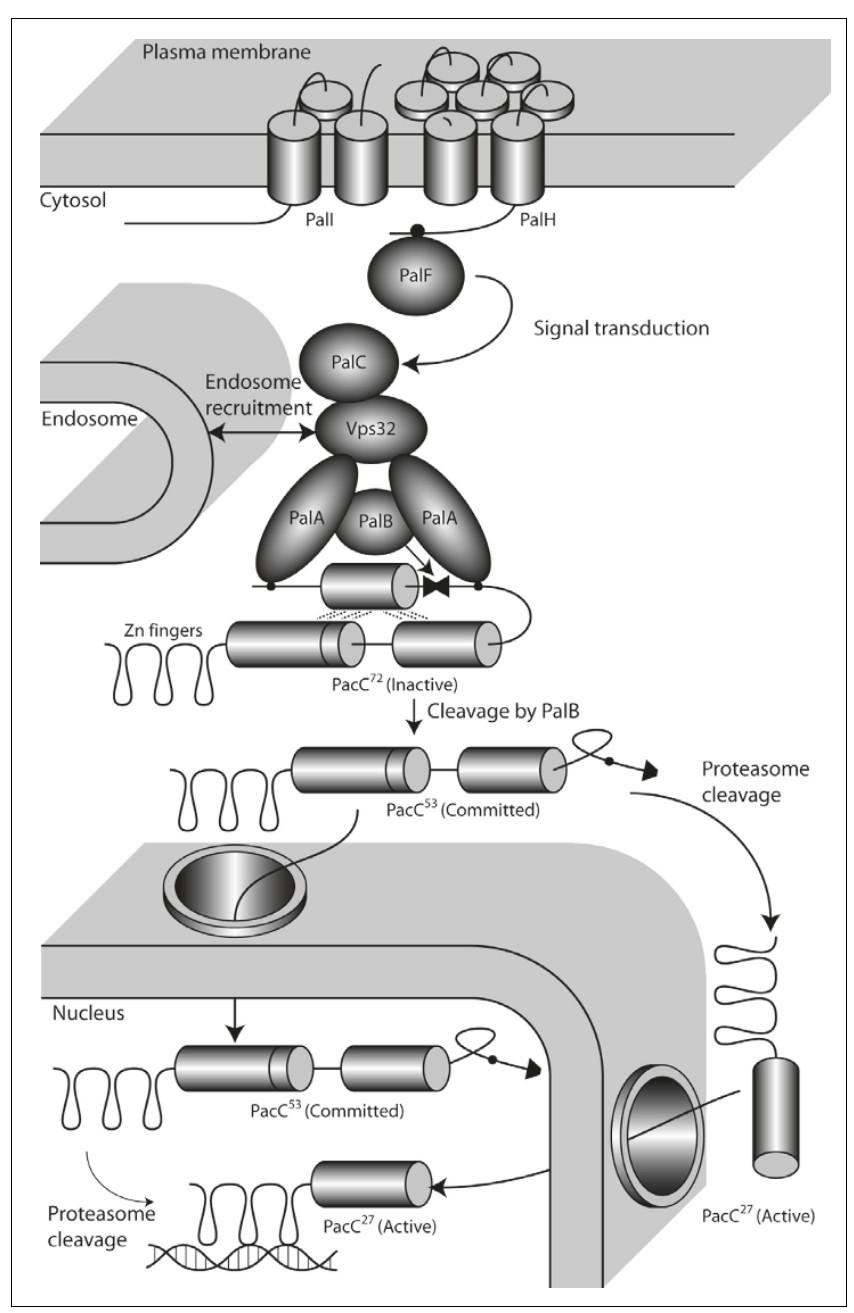

Figure 5

Model of $\mathrm{pH}$ sensing and regulation in $\mathrm{A}$. nidulans. Black circles denote sites of protein-protein interaction, as does the overlap of two protein domains. The dotted lines of the closed conformation of $\mathrm{PacC}$ illustrate non-covalent interaction protecting the proteasome cleavage site. $V_{p s} 32$ is a part of the ESCRT-III complex that recruits to the endosome. The figure is adapted from reference [34] with information added from references $[40,41,45,64]$.

regulation by ambient $\mathrm{pH}$ in $A$. niger. This study examines the response to ambient $\mathrm{pH}$ by the combination of results from two distinct strategies. One is a strictly hypothesisdriven application of stoichiometric modeling, with which the modeling results are compared with reported observations to test the hypothesis of $A$. niger being optimized for acidification at any given $\mathrm{pH}$ through the course of evolution. The other study, the transcriptomic, is a more-classic application of systems biology, in that it is a data-driven study, and the analysis both gives specific directly applicable results and allows the generation of new hypotheses on $\mathrm{pH}$ regulation.

The modeling part of the study showed that the optimal $\mathrm{pH}$ intervals for production of acids, and the types of acids produced at certain $\mathrm{pH}$ values, can to a certain extent be 
Table 2

\begin{tabular}{|c|c|c|}
\hline \multirow[t]{2}{*}{ Gene } & \multicolumn{2}{|c|}{ ORFs } \\
\hline & A. nidulans & A. niger \\
\hline palA & AN435I & 119792 \\
\hline palB & AN0256 & 171058 \\
\hline palc & AN7560 & 48740 \\
\hline palF & ANI 844 & Not found* \\
\hline palH & AN6886 & 120044 \\
\hline pall & AN4853 & 52449 \\
\hline vps32/snf7 & AN4240 & 136905 \\
\hline pacC & AN2855 & 47049 \\
\hline
\end{tabular}

The $A$. niger open reading frames (ORFs) were identified by using bidirectional best blast hits.

*No hit for palF was found in the publicly available genome sequence for A. niger ATCC I015, but a near-identical hit was found on the right arm of chromosome $\mathrm{VI}$ in the finished version of the genome sequence.

explained and simulated for citrate and oxalate, based on an assumption of an evolutionary selection for efficient acidification. The success of this approach to modeling acid production strongly suggests that $A$. niger has not evolved to outgrow its competitors such as Escherichia coli or to have a very efficient glucose uptake as does Saccharomyces cerevisiae. Instead, $A$. niger metabolism seems to be optimized to produce the most protons from the sparse nutrients available in a saprophytic environment. This also implies that acid production in A. niger does not stem from overflow metabolism, but rather from an objective of proton production, at least for oxalic acid and citric acid.

The inability of the model to predict the $\mathrm{pH}$ optimum of gluconic acid production suggests that the main objective of gluconic acid production is not related to acidification of the medium. This is supported by the detailed on-line fermentation chromatography results presented by van de Merbel et al. [47], in which glucose in the medium is rapidly converted fully into gluconic acid, which thereafter functions as a substrate for the rest of the fermentation. As the modeling can compute conditions only after a full degradation of the substrates, this will not show in the model. The production of gluconic acid thereby seems to be a method of making glucose unavailable to other competing organisms. This is also supported by the observations of the physiological study shown in Figure 3, in which gluconic acid produced early in the fermentation is seen to be reconsumed later.

Although the cellular response to manganese deficiency is undoubtedly complex, as the work of Dai et al. [18] and others have shown, it is interesting that the results of Ruijter et al. [3] indicate that the citrate production becomes insensitive to manganese concentrations by the deletion of glucose oxidase and oxaloacetate hydrolase. Whereas the applied model does not include the effects of manganese deficiency, it was able to replicate the effect of citrate being produced in an oxalatedeficient strain. The absence of manganese presumably has other effects that improve citrate yields, but it seems, based on these results, that one reason for its effect is the dependence of oxaloacetate hydrolase on manganese.

In modeling acid production with optimization for growth (see Additional data file 1), the biomass production increases as a function of $\mathrm{pH}$. This is opposite that observed in the in vivo experiments. One reason for this effect is that it is very unlikely that the acid-regulation systems of $A$. niger were evolved in a medium as heavily buffered as a controlled bioreactor with $\mathrm{pH}$ regulation. It is thus efficient at a high $\mathrm{pH}$ to sacrifice biomass production for the production of large amounts of protons to reduce the $\mathrm{pH}$ quickly and to reduce this production at low $\mathrm{pH}$ values. We have not attempted to model this behavior, as there are very few available detailed data on acid production at different $\mathrm{pH}$ values. The work by Pedersen et al. [48] has sufficient detail for one level of $\mathrm{pH}$, and thus this was used to approximate a constant ratio of protons to biomass. Although the assumption of a constant proton/biomass ratio is not valid over the full range of $\mathrm{pH}$, it does allow us to study the simulated response in detail across the range of $\mathrm{pH}$ shown. Changing the proton/biomass ratio for individual $\mathrm{pH}$ value changes only the magnitude of the acid production and not the species.

In examining the transcriptional response, it was interesting - in the context of organic acids - to see that oahA and goxC are expressed and regulated, whereas no significant acid production occurs at the time of sampling for transcriptome analysis (Table 1). This suggests retention of the acid inside the cells or regulation of the gene product at a post-translational level.

In total, the number of genes influenced by ambient $\mathrm{pH}$ was surprisingly high. Although the transcriptional analysis is to some extent confounded by an effect on 'domestic' genes, the remaining response (2,022 genes) is still high. This response is not unlikely, as A. niger growing in nature acidifies the surroundings, thus living through a scale of $\mathrm{pH}$ values. This presumably requires a flexible and dynamic response of a large number of genes. Another point is, as Arst and Peñalva [49] correctly argue, when transcription of a gene is affected by ambient $\mathrm{pH}$, this does not necessarily mean that it is regulated by $\mathrm{pH}$. It may be an indirect consequence caused by differences in uptake efficiencies, intracellular metabolite levels, or other indirect effects. Most likely, a combination of the two is what we see here. For this purpose, the clustering and following identification of 109 genes with direct correlations with $\mathrm{pH}$ levels have proven to be a powerful method of data reduction. 
The applied two-step clustering method allows differentiation between different effects, although it cannot determine which clusters of genes are directly or indirectly influenced by $\mathrm{pH}$. One interesting application of this transcription study and the clustering is the prediction of regulatory motifs based on the transcription profiles. The predicted motifs are very likely to have the proposed function of increasing transcription with higher levels of $\mathrm{pH}$, because one of the detected motifs was previously described to have this function. Although this, in theory, could be done for all of the 162 identified clusters, the performed predictions are limited to those described in the main matter of this study, but details on the clusters (see Additional data files 4 and 5) will support further investigation of other hypotheses. One obvious application of this is the identification of putative transcription factors regulated by ambient $\mathrm{pH}$. We are currently constructing knockout strains for a large number of these.

The analysis of the clusters also includes the combination with data on the physical location of the genes. For the clusters predicted to be involved in secondary metabolite production, this physical location adds considerable value to the transcriptome analysis. It is confirmed that putative secondary metabolite clusters are transcriptionally regulated by $\mathrm{pH}$. Even so, some of the identified co-regulated gene clusters may be artefacts, because of errors in predicting gene starts/ stops. For example, if a gene erroneously has been predicted to be several genes, these will be seen as being co-regulated in the transcriptome analysis. Another likely explanation is that they are co-regulated by a common promoter region. However, for clusters of more than two genes, this is unlikely to be the case.

In a comparison of the modeling and the in vivo experiments, the predicted values correspond well with the profiles of oxalate production and the known literature. At all levels of $\mathrm{pH}$, oxalate is a preferred acid (second to gluconate). As manganese was present in the medium and oahA was present in the strain, the funneling of carbon into citrate at lower $\mathrm{pH}$ could not be observed. As described in the work of Dai et al. [18] and Ruijter et al. [3], this is to be expected. Furthermore, when examining the transcription levels of oahA, which is found in subset $\mathrm{E}$ of Figure 4, they are on average 83 times higher at $\mathrm{pH} 2.5$ compared with 6.o. This regulation counteracts citrate production. Thus, the predictions of the model are indeed valid, but the predicted (and known) optimum of citrate production are not replicated in the cultivations because of unknown factors.

The first steps toward understanding the $\mathrm{pH}$-signaling pathway of $A$. niger, a pathway of great potential importance for the fermentation industry, are provided. The investigation of the A. niger homologue to the - in A. nidulans - welldescribed pal pH-signaling pathway showed that all components are present in $A$. niger and are expressed independent of $\mathrm{pH}$. The uniqueness of this pathway makes it more than likely that these genes code for orthologues of the A. nidulans genes. However, a classic phenotypical characterization of mutants is still necessary to establish the function finally, but with this study, the targets for this characterization are now firmly established.

\section{Conclusions}

We have shown through genome-scale modeling that the assumption of evolutionary selection for efficient acidification allows the reproduction of the $\mathrm{pH}$ optimum for production of citrate and oxalate by $A$. niger. Furthermore, our results indicate that high-yield gluconic acid production has not evolved as a trait for acidification of the growth habitat. Transcriptome analysis of $A$. niger cultures grown at three levels of $\mathrm{pH}$ showed 6,228 genes for which the transcription levels were significantly changed by direct and indirect effects of ambient pH. A two-step clustering method and GO term overrepresentation analysis identified 2,022 genes more likely to be influenced by $\mathrm{pH}$ and 109 genes with transcription levels directly corresponding to the level of $\mathrm{pH}$. Analysis of these genes showed a strong co-regulation of catR and goxA. By combining genome coordinates with transcriptome profiles and predicted gene functions, secondary metabolite clusters found to be regulated by $\mathrm{pH}$ were identified. The cisacting promoter motifs increasing transcription with higher levels of $\mathrm{pH}$ were identified, and a strategy for finding promoter motifs for other transcription profiles was presented. By using a combination of transcriptome data and sequence comparisons, the candidate orthologues of the $A$. nidulans $\mathrm{Pal} / \mathrm{PacC} \mathrm{pH}-$ regulation pathway were identified in $A$. niger. The conservation of this system supports that filamentous fungi have evolved to use several strategies for outcompeting rival organisms: an aggressive acidification of the microenvironment combined with storing the available glucose as gluconic acid.

\section{Materials and methods \\ Modeling acid production}

For each value of $\mathrm{pH}$, a set of reactions was added to a genome-scale stoichiometric model of $A$. niger metabolism [7], thereby creating a model for each $\mathrm{pH}$ value. The reactions set consisted of seven reactions, one for each of the acids included in the model. Each reaction contains the fully protonated acid in an equilibrium with the partially unprotonated acid species and a number of protons. This number was calculated for each $\mathrm{pH}$ and acid by using the acid disassociation constant equation as shown in Equation 2:

$$
K_{a}=\frac{\left[H^{+}\right]\left[A^{-}\right]}{[H A]}=10^{-p H} \frac{\left[A^{-}\right]}{[H A]} \Rightarrow
$$




$$
\frac{\left[\mathrm{A}^{-}\right]}{[H A]}=\frac{K_{a}}{10^{-p H}}
$$

In the case of polyprotic acids such as citric acid, a set of coupled equations - one for each acid group - was used. An example for citrate at $\mathrm{pH} 4.5$ is shown in Equation 3 (see Additional data file 6 for the full set):

$$
C T e<->C I T-e+13196 H+e
$$

The entity CIT-e of Equation 3 is a mixed species, composed of citric acid molecules in various degrees of deprotonation, all in equilibrium at the given $\mathrm{pH}$. It is assumed that the acids are transported across the cytoplasmic membrane fully protonated.

Modeling of acid production was performed by using stoichiometric matrices and linear programming for solving them, as described in reference [7]. Either the solving objective was a maximization of proton production with a fixed biomass production of $1 \mathrm{~g}$ or maximization for growth (growth-coupled proton production). For modeling of growth-coupled proton production, the biomass equation added a demand for 15.3 mmole of protons per gram of dry weight. This value was calculated from the oxalate and citrate yields of a pH 6.0 cultivation described by Pedersen et al. [48]. All simulations were performed with 100 mmole glucose and unlimited ammonium as substrates.

\section{Fermentation protocol \\ Strains}

The strain used was $A$. niger BO-1, obtained from Novozymes A/S (Kalundborg, Denmark) and maintained as frozen spore suspensions at $-80^{\circ} \mathrm{C}$ in $20 \%$ glycerol.

\section{Growth media}

Complex medium: $2 \mathrm{~g} / \mathrm{L}$ yeast extract, $3 \mathrm{~g} / \mathrm{L}$ tryptone, $10 \mathrm{~g} / \mathrm{L}$ glucose monohydrate, $20 \mathrm{~g} / \mathrm{L}$ agar, $0.52 \mathrm{~g} / \mathrm{L} \mathrm{KCl}, 0.52 \mathrm{~g} / \mathrm{L}$ $\mathrm{MgSO}_{4} \cdot 7 \mathrm{H}_{2} \mathrm{O}, 1.52 \mathrm{~g} / \mathrm{L} \mathrm{KH}_{2} \mathrm{PO}_{4}$ and $1 \mathrm{ml} /$ Lof trace elements solution. Trace element solution: $0.4 \mathrm{~g} / \mathrm{L} \mathrm{CuSO}_{4} \cdot 5 \mathrm{H}_{2} \mathrm{O}$, 0.04 $\mathrm{g} / \mathrm{L} \quad \mathrm{Na}_{2} \mathrm{~B}_{4} \mathrm{O}_{7} \cdot 10 \mathrm{H}_{2} \mathrm{O}, \quad 0.8 \mathrm{~g} / \mathrm{L} \quad \mathrm{FeSO}_{4} \cdot 7 \mathrm{H}_{2} \mathrm{O}, \quad 0.8 \mathrm{~g} / \mathrm{L}$ $\mathrm{MnSO}_{4} \cdot \mathrm{H}_{2} \mathrm{O}$, $0.8 \mathrm{~g} / \mathrm{L} \mathrm{Na}_{2} \mathrm{MoO}_{4} \cdot 2 \mathrm{H}_{2} \mathrm{O}, 8 \mathrm{~g} / \mathrm{L} \mathrm{ZnSO}_{4} \cdot 7 \mathrm{H}_{2} \mathrm{O}$. Batch cultivation medium: $20 \mathrm{~g} / \mathrm{L}$ glucose monohydrate, 2.5 $\mathrm{g} / \mathrm{L}\left(\mathrm{NH}_{4}\right)_{2} \mathrm{SO}_{4}, 0.75 \mathrm{~g} / \mathrm{L} \mathrm{KH}_{2} \mathrm{PO}_{4}, 1.0 \mathrm{~g} / \mathrm{L} \mathrm{MgSO}_{4} \cdot 7 \mathrm{H}_{2} \mathrm{O}, 1 \mathrm{~g} /$ $\mathrm{L} \mathrm{NaCl}, 0.1 \mathrm{~g} / \mathrm{L} \mathrm{CaCl}_{2} \cdot 2 \mathrm{H}_{2} \mathrm{O}$, $0.05 \mathrm{ml} / \mathrm{L}$ antifoam 204 (SigmaAldrich, Brøndby, Denmark) and $1 \mathrm{ml} / \mathrm{L}$ trace element solution. Trace element solution composition: $7.2 \mathrm{~g} / \mathrm{L}$ $\mathrm{ZnSO}_{4} \cdot 7 \mathrm{H}_{2} \mathrm{O}, 0.3 \mathrm{~g} / \mathrm{L} \mathrm{NiCl}_{2} \cdot 6 \mathrm{H}_{2} \mathrm{O}, 6.9 \mathrm{~g} / \mathrm{L} \mathrm{FeSO}_{4} \cdot 7 \mathrm{H}_{2} \mathrm{O}, 3.5$ $\mathrm{g} / \mathrm{L} \mathrm{MnCl}_{2} \cdot 4 \mathrm{H}_{2} \mathrm{O}$, and $1.3 \mathrm{~g} / \mathrm{L} \mathrm{CuSO}_{4} \cdot 5 \mathrm{H}_{2} \mathrm{O}$.

\section{Preparation of inoculum}

Fermentations were initiated by spore inoculation to a final concentration of $2 \times 10^{-9}$ spores/L. Spores were propagated on complex media plates and incubated for 7 to 8 days at $30^{\circ} \mathrm{C}$ before being harvested with $10 \mathrm{ml}$ of $0.01 \%$ Tween 80 .

\section{Batch cultivations}

Batch cultivations were performed in 2-L Braun fermenters with a working volume of $1.6 \mathrm{~L}$, equipped with three Rushton four-blade disc turbines. The bioreactor was sparged with air, and the concentrations of oxygen and carbon dioxide in the exhaust gas were measured in a gas analyzer. The temperature was maintained at $30^{\circ} \mathrm{C}$. The $\mathrm{pH}$ was controlled by automatic addition of $2 \mathrm{M} \mathrm{NaOH}$. Agitation and aeration were controlled throughout the cultivations. For inoculation of the bioreactor, the $\mathrm{pH}$ was adjusted to 2.5; stirring rate, $100 \mathrm{rpm}$; and aeration, 0.1 volumes of air per volume of fluid per minute (vvm). After germination, the stirring rate was increased to $300 \mathrm{rpm}$, and the air flow, to $0.5 \mathrm{vvm}$. At 11 to 12 hours after inoculation, the stirring rate was increased to 600 $\mathrm{rpm}$, and the air flow, to $1 \mathrm{vvm}$. When the $\mathrm{CO}_{2}$ in the exhaust gas reached a value of $0.1 \%$ (early growth phase), the stirring rate was set to $1,000 \mathrm{rpm}$. Additionally, at this level of $\mathrm{CO}_{2}$, the $\mathrm{pH}$ was slowly increased to 4.5 or 6.0 with a drop of $2 \mathrm{M}$ $\mathrm{NaOH}$ every 10 seconds. For the cultivations at $\mathrm{pH} 2.5, \mathrm{pH}$ was kept constant throughout the fermentation.

The concentrations of oxygen and carbon dioxide in the exhaust gas were monitored with a gas analyzer (1311 Fast response Triple gas, Innova combined with multiplexer controller for Gas Analysis MUX10o, B. Braun Biotech International (Melsungen, Germany)).

\section{Sampling}

Cell dry weight was determined by using nitrocellulose filters (pore size, $0.45 \mu \mathrm{m}$; Pall Corporation, East Hills, NY, USA). The filters were predried in a microwave oven at $150 \mathrm{~W}$ for 15 minutes, cooled in a desiccator, and subsequently weighed. A known volume of cell culture was filtered, and the residue was washed with $0.9 \% \mathrm{NaCl}$ and dried on the filter for 15 minutes in a microwave oven at $150 \mathrm{~W}$ and cooled in a desiccator. The filtrate was saved for quantification of sugars and extracellular metabolites and stored at $-80^{\circ} \mathrm{C}$. The filter was weighed again, and the cell mass concentration was calculated. These values were used to calculate maximal specific growth rates. For gene-expression analysis, mycelium was harvested at the mid to late exponential phase by filtration through sterile Mira-Cloth (Calbiochem, San Diego, CA, USA) and washed with phosphate-buffered saline (PBS) $(8 \mathrm{~g} / \mathrm{L} \mathrm{NaCl}, 0.20 \mathrm{~g} / \mathrm{L}$ $\mathrm{KCl}, 1.44 \mathrm{~g} / \mathrm{L} \mathrm{Na}_{2} \mathrm{HPO}_{4}$, and $0.24 \mathrm{~g} / \mathrm{L} \mathrm{KH}_{2} \mathrm{PO}_{4}$ in distilled water). The mycelium was quickly dried by squeezing, and subsequently frozen in liquid nitrogen. Samples were stored at $-80^{\circ} \mathrm{C}$ until RNA extraction.

\section{Quantification of sugars and extracellular metabolites}

The concentrations of sugar and organic acids in the filtrates were determined by using HPLC on an Aminex HPX-87H ion-exclusion column (BioRad, Hercules, CA, USA). The column was eluted at $60^{\circ} \mathrm{C}$ with $5 \mathrm{mM} \mathrm{H}_{2} \mathrm{SO}_{4}$ at a flow rate of 0.6 
$\mathrm{ml} / \mathrm{min}$. Metabolites were detected with a refractive index detector and a UV detector.

\section{Calculation of maximum specific growth rates}

The maximal growth rate was determined by performing exponential regressions on the data points from the exponential phase (defined as the part of the growth curve that exhibited linear increase in a single-log plot) for each of the nine experiments. Means and standard deviations were calculated for each set of triplicates.

\section{Transcriptome analysis}

\section{Extraction of total RNA}

From 40 to $50 \mathrm{mg}$ of frozen mycelium was placed in a 2-ml Eppendorf tube, precooled in liquid nitrogen, containing three steel balls (two balls with a diameter of $2 \mathrm{~mm}$ and one ball with a diameter of $5 \mathrm{~mm}$ ). The tubes were then shaken in a Mixer Mill, at $5^{\circ} \mathrm{C}$ for 10 minutes, until the mycelia were ground to powder. Total RNA was isolated from the powder by using the Qiagen RNeasy Mini Kit, according to the protocol for isolation of total RNA from plant and fungi. The quality of the extracted total RNA was assessed by using a BioAnalyzer 2100 (Agilent Technologies, Inc., Santa Clara, CA, USA), and the quantity determined by using a spectrophotometer (GE Healthcare Bio-Sciences AB, Uppsala, Sweden). The total RNA was stored at $-80^{\circ} \mathrm{C}$ until further processing.

\section{Preparation of biotin-labeled cRNA and microarray processing} Fragmented biotin-labeled cRNA $(15 \mu \mathrm{g})$ was prepared from $5 \mu \mathrm{g}$ of total RNA and hybridized to the 3AspergDTU GeneChip [50] according to the Affymetrix GeneChip Expression Analysis Technical Manual [51].

cRNA was quantified in a spectrophotometer (same as described earlier). cRNA quality was assessed by using a BioAnalyzer. A GeneChip Fluidics Station FS-40o (fluidics protocol FS450_o01) and a GeneChip Scanner 3000 were used for hybridization and scanning.

The scanned probe array images (.DAT files) were converted into .CEL files by using the GeneChip Operating Software (Affymetrix).

\section{Analysis of transcription data}

Affymetrix CEL-data files were preprocessed by using the statistical language and environment $\mathrm{R}$ [52] version 2.5.1. The probe intensities were normalized for background by using the robust multiarray average (RMA) method [53] with only perfect match (PM) probes. Normalization was performed subsequently by using the quantiles algorithm [54]. Geneexpression values were calculated from the PM probes with the median polish summary method [53]. All statistical preprocessing methods were used by invoking them through the Affy package [55].
Statistical analysis was applied to determine genes subject to differential transcriptional regulation. The limma package [56] was used to perform moderated $t$ tests between two sets of triplicates from each pH level. Empiric Bayesian statistics were used to moderate the standard errors within each gene, and Benjamini-Hochberg's method [57], to adjust for multitesting. A cut-off value of adjusted $P<0.05$ was set to assess statistical significance.

Normalized and raw data values are deposited with Gene Expression Omnibus [GEO:GSE11725].

\section{Clustering}

The 6,228 genes that showed significant changes in expression indices in one or more pairwise comparisons were sorted into groups based on the direction of their response in the three different sets of conditions. These groups were divided into a varying number of subgroups (clusters) by using the clustering algorithm ClustreLustre [58], with k-means normalization. The groups were divided until all clusters had a minimum separation distance of 1.01. This number was picked empirically and was the minimal distance at which each cluster still had a distinct regulation pattern.

\section{Identification of co-regulated gene clusters}

Co-regulated gene clusters were defined in this study as genes on the same scaffold that are separated by no more than 5 kilobases, significantly regulated in one or more pairwise comparisons, and having the same regulation pattern as determined by the detailed clustering by using ClusterLustre.

\section{Prediction of conserved motifs}

Conserved motifs were predicted by using R 2.6.2 [52] with the Cosmo package v. 1.4.o [59]. Default settings were used with the following exceptions: A background Markov model was computed by using the intergenic regions from scaffold 1 of the A. niger ATCC 1015 genome sequence. Intergenic regions containing unknown bases (Ns) were pruned from the training set, amounting to $1.7 \mathrm{Mb}$ in 1,214 sequences. The Two-Component-Mixture (TCM), One Occurrence Per Sequence (OOPS) and Zero Or One Occurrence Per Sequence (ZOOPS) motif models were used to search for conserved motifs. For all query sequences 1 ,ooo base pairs upstream of the start codon of the gene or of the predicted transcription start were, if any was found. If a transcription start was predicted, the sequence from this base pair and to the start codon was included as well, thus increasing the length of sequence to more than 1 kilobase.

\section{GO-term enrichment analysis}

Significantly regulated subsets of genes were examined for GO-term enrichment by using R-2.5.1 [52] with BioConductor [6o] and the topGO-package v. 1.2.1 by using the elim algorithm to remove local dependencies between GO terms [61]. GO-term assignments were based on automatic annota- 
tion of the $A$. niger ATCC 1015 v1.o gene models. Where nothing else is noted, $P<0.05$ is used as the cutoff for significance.

\section{Abbreviations}

JGI: Joint Genome Institute; ORFs: open reading frames; PBS: phosphate-buffered saline; ppb: parts per billion; vvm: volumes of air per volume of fluid per minute.

\section{Authors' contributions}

MRA wrote the manuscript, analyzed data, designed the experiments, and performed a part of the microarray hybridization. LL wrote the expansion of the model, analyzed data, and performed bioreactor cultivations and the majority of the microarray hybridization. JN designed the experiments and supervised the work.

\section{Additional data files}

The following additional data are available with the online version of this article. Additional data file 1 is a figure containing an overview of modeled acid production as a function of $\mathrm{pH}$ maximizing for growth coupled with acid (proton) production. Additional data file 2 is a figure containing an overview of modeled acid production as a function of $\mathrm{pH}$, maximizing for proton production with fixed growth. Additional data file 3 is a text file with GO term overrepresentation results for all clusters of Additional data file 5 except cluster $\mathrm{D}$, which has only one gene. For each of the three ontologies (metabolic function, biologic process, and cellular component) is shown the significant terms (p.elim < 0.05). Additional data file 4 is a figure showing the clusters of genes coregulated by ambient $\mathrm{pH}$. Cluster $\mathrm{D}$ is not shown, as it contains only one gene. The clusters are grouped based on statistical significance in pairwise comparisons of transcriptome data at $\mathrm{pH}$ values of $2.5,4.5$, and 6.o. Each cluster has nine values. The first three are biologic replicates at $\mathrm{pH} 2.5$; the middle three are at $\mathrm{pH} 4.5$; and the last three are from $\mathrm{pH}$ 6.o. The genes are clustered by using Matlab and the ClustreLustre algorithm [58]. Additional data file 5 is a table containing the clustering of $A$. niger genes with significantly changed expression indices. The HiLo, MeLo, and HiMe columns are $\log 2$ ratios of gene-expression indices in comparisons of $\mathrm{pH}$ 6.o (Hi), pH 4.5 (Me), and pH 2.5 (Lo). Negative values mean that the index was higher in the second condition. If the comparison was not significant, a N/A is shown. Annotations are manually extracted from the Joint Genome Institute (JGI) website [62] and are the manual annotation (if that was present), or a general Interpro or GO-term prediction (if no manual annotation was present). A '-' means that no putative function could be assigned. The Colocalized column: Genes with the same number are colocalized. The Sec Metabolites column: Genes that are believed to be in a colocalized, co-regulated secondary metabolite cluster are marked with numbers. Additional data file 6 is a table of the proton-creating reactions of the acid-production model that were added to the previously described genome-scale stoichiometric model of A. niger [7].

\section{Acknowledgements}

M.R.A. and L.L. were funded by the Danish Research Agency for Technology and Production. Antonio Diego Martinez is acknowledged for kindly supplying the genome coordinates for the predicted genes of A. niger ATCC 1015. We thank Lene Christiansen for indispensable practical assistance with array preparations, Tina Johansen for excellent technical support on HPLC and fermentation equipment, Martin Nielsen for assisting with the design of a stable and dynamic $\mathrm{pH}$-controlling algorithm for the bioreactors, Kenneth Bruno for inspiring discussions on acid production in A. niger, Scott E. Baker for allowing the use of the finished version of the genome sequence of A. niger ATCC I0I5, and Michael L. Nielsen for critical reading of the manuscript. The un-named reviewers also greatly improved on the discussion of the data.

\section{References}

I. Karaffa L, Kubicek CP: Aspergillus niger citric acid accumulation: do we understand this well working black box? Appl Microbiol Biotechnol 2003, 61: 189-196.

2. Pedersen $\mathrm{H}$, Hjort $\mathrm{C}$, Nielsen J: Cloning and characterization of oah, the gene encoding oxaloacetate hydrolase in Aspergillus niger. Mol Gen Genet 2000, 263:28I-286.

3. Ruijter GJG, Vondervoort PJI van de, Visser J: Oxalic acid production by Aspergillus niger: an oxalate-non-producing mutant produces citric acid at $\mathbf{p H ~} 5$ and in the presence of manganese. Microbiology 1999, 145:2569-2576.

4. Heinrich M, Rehm H: Formation of gluconic acid at low pH-values by free and immobilized Aspergillus niger cells during citric acid fermentation. Appl Microbiol Biotechnol 1982, I 5:88-92.

5. Witteveen FB, Vondervoort PJ van de, Broeck $\mathrm{HC}$ van den, van Engelenburg AC, de Graaff LH, Hillebrand MH, Schaap PJ, Visser J: Induction of glucose oxidase, catalase, and lactonase in Aspergillus niger. Curr Genet 1993, 24:408-416.

6. Magnuson J, Lasure L: Organic acid production by filamentous fungi. In Advances in fungal biotechnology for industry, agriculture and medicine Edited by: Tkacz JS, Lange L. New York: Kluwer/Plenum; 2004:307-340

7. Andersen M, Nielsen M, Nielsen J: Metabolic model integration of the bibliome, genome, metabolome and reactome of Aspergillus niger. Mol Syst Biol 2008, 4: 178.

8. Hombergh J van den, MacCabe A, Vondervoort P van de, Visser J: Regulation of acid phosphatases in an Aspergillus niger pacC disruption strain. Mol Gen Genet 1996, 25 I:542-550.

9. Baker S: Aspergillus niger genomics: past, present and into the future. Med Mycol 2006, 44:SI7-S2I.

10. Frisvad J, Smedsgaard J, Samson R, Larsen T, Thrane U: Fumonisin $B_{2}$ production by Aspergillus niger. J Agric Food Chem 2007, 55:9727-9732.

II. Abarca ML, Bragulat MR, Castella G, Cabanes FJ: Ochratoxin A production by strains of Aspergillus niger var. niger. Appl Environ Microbiol 1994, 60:2650-2652.

12. Samson RA, Houbraken JA, Kuijpers AF, Frank JM, Frisvad JC: New ochratoxin A or sclerotium producing species in Aspergillus section Nigri. Stud Mycol 2004, 50:45-61.

13. Shah A, Tilburn J, Adlard M, Arst $\mathrm{H}$ : $\mathbf{p H}$ regulation of penicillin production in Aspergillus nidulans. FEMS Microbiol Lett I99I, 61:209-2I2

14. Hesse SJA, Ruijter GJG, Dijkema C, Visser J: Intracellular pH homeostasis in the filamentous fungus Aspergillus niger. Eur J Biochem 2002, 269:3485-3494.

15. Peñalva M, Arst H Jr: Regulation of gene expression by ambient pH in filamentous fungi and yeasts. Microbiol Mol Biol Rev 2002, 66:426-446.

16. Peñalva $M$, Arst $H$ Jr: Recent advances in the characterization of ambient $\mathrm{pH}$ regulation of gene expression in filamentous fungi and yeasts. Annu Rev Microbiol 2004, 58:425-45I.

17. Kubicek CP, Schreferl-Kunar G, Wöhrer W, Röhr M: Evidence for a cytoplasmic pathway of oxalate biosynthesis in Aspergillus niger. Appl Environ Microbiol 1988, 54:633-637. 
18. Dai Z, Mao X, Magnuson JK, Lasure LL: Identification of genes associated with morphology in Aspergillus niger by using suppression subtractive hybridization. Appl Environ Microbiol 2004, 70:2474-2485

19. Xu B, Madrit C, Röhr M, Kubicek C: The influence of type and concentration of the carbon source on production of citric acid by Aspergillus niger. Appl Microbiol Biotechnol 1989, 30:553-558.

20. Ruijter GJG, Visser J: Carbon repression in aspergilli. FEMS Microbiol Lett 1997, I 5 I:103-I|4.

2I. Strauss J, Horvath HK, Abdallah BM, Kindermann J, Mach RL, Kubicek $\mathrm{CP}$ : The function of CreA, the carbon catabolite repressor of Aspergillus nidulans, is regulated at the transcriptional and post-transcriptional level. Mol Microbiol 1999, 32:169-I78.

22. Fowler T, Rey M, Vähä-Vahe P, Power S, Berka R: The catR gene encoding a catalase from Aspergillus niger primary structure and elevated expression through increased gene copy number and use of a strong promoter. Mol Microbiol 1993, 9:989-998

23. Witteveen $C$, Veenhuis $M$, Visser J: Localization of glucose oxidase and catalase activities in Aspergillus niger. Appl Environ Microbiol 1992, 58: I 190-II94.

24. Kriechbaum M, Heilmann $H$, Wientjes F, Hahn M, Jany K, Gassen $H$, Sharif $F$, Alaeddinoglu $G$ : Cloning and DNA sequence analysis of the glucose oxidase gene from Aspergillus niger NRRL-3. FEBS Lett 1989, 255:63-66.

25. Frederick KR, Tung J, Emerick RS, Masiarz FR, Chamberlain SH, Vasavada $A$, Rosenberg S: Glucose oxidase from Aspergillus niger. J Biol Chem 1990, 265:3793-3802

26. MacCabe A, Hombergh J van den, Tilburn J, Arst H Jr, Visser J: Identification, cloning and analysis of the Aspergillus niger gene pacC, a wide domain regulatory gene responsive to ambient pH. Mol Gen Genet 1996, 250:367-374.

27. Sarkar S, Caddick M, Bignell E, Tilburn J, Arst H Jr: Regulation of gene expression by ambient $\mathrm{pH}$ in Aspergillus: genes expressed at acid pH. Biochem Soc Trans 1996, 24:360-363.

28. Tilburn J, Sarkar S, Widdick D, Espeso E, Orejas M, Mungroo J, Peñalva $M$, Arst $H J$ : The Aspergillus PacC zinc finger transcription factor mediates regulation of both acid- and alkalineexpressed genes by ambient pH. EMBO J 1995, I 4:779-790.

29. Orejas M, Espeso E, Tilburn J, Sarkar S, Arst H Jr, Peñalva M: Activation of the Aspergillus PacC transcription factor in response to alkaline ambient $\mathrm{pH}$ requires proteolysis of the carboxyterminal moiety. Genes Dev 1995, 9:1622-1632.

30. Pel HJ, de Winde JH, Archer DB, Dyer PS, Hofmann G, Schaap PJ, Turner G, de Vries RP, Albang R, Albermann K, Andersen MR, Bendtsen JD, Benen JA, Berg M van den, Breestraat S, Caddick MX, Contreras R, Cornell M, Coutinho PM, Danchin EG, Debets AJ, Dekker P, van Dijck PW, van Dijk A, Dijkhuizen L, Driessen AJ, d'Enfert C, Geysens S, Goosen C, Groot GS, et al.: Genome sequencing and analysis of the versatile cell factory Aspergillus niger CBS 5 I3.88. Nat Biotechnol 2007, 25:22I-23I.

31. Mingot J, Tilburn J, Díez E, Bignell E, Orejas M, Widdick D, Sarkar S, Brown C, Caddick M, Espeso E, Arst H Jr, Peñalva M: Specificity determinants of proteolytic processing of Aspergillus PacC transcription factor are remote from the processing site, and processing occurs in yeast if $\mathrm{pH}$ signaling is bypassed. $\mathrm{Mol}$ Cell Biol 1999, 19:1390-1400.

32. Espeso E, Roncal T, Díez E, Rainbow L, Bignell E, Alvaro J, Suárez T, Denison S, Tilburn J, Arst H Jr, Peñalva M: On how a transcription factor can avoid its proteolytic activation in the absence of signal transduction. EMBO J 2000, 19:719-728.

33. Díez E, Alvaro J, Espeso E, Rainbow L, Suárez T, Tilburn J, Arst H Jr, Peñalva M: Activation of the Aspergillus PacC zinc finger transcription factor requires two proteolytic steps. EMBO J 2002, 2 I:1350-1359.

34. Arst $\mathrm{H}$, Peñalva $\mathrm{M}$ : $\mathbf{p H}$ regulation in Aspergillus and parallels with higher eukaryotic regulatory systems. Trends Genet 2003, 1 9:224-231.

35. Caddick M, Brownlee A, Arst H: Regulation of gene expression by $\mathrm{pH}$ of the growth medium in Aspergillus nidulans. Mol Gen Genet 1986, 203:346-353.

36. Maccheroni W Jr, May G, Martinez-Rossi N, Rossi A: The sequence of palf, an environmental $\mathrm{pH}$ response gene in Aspergillus nidulans. Gene 1997, 194:163-167.

37. Arst $\mathrm{HJ}$, Bignell E, Tilburn J: Two new genes involved in signaling ambient $\mathrm{pH}$ in Aspergillus nidulans. Mol Gen Genet 1994, 245:787-790.
38. Denison S, Negrete-Urtasun S, Mingot J, Tilburn J, Mayer W, Goel A, Espeso E, Peñalva M, Arst HJ: Putative membrane components of signal transduction pathways for ambient $\mathrm{pH}$ regulation in Aspergillus and meiosis in Saccharomyces are homologous. Mol Microbiol 1998, 30:259-264.

39. Negrete-Urtasun S, Reiter W, Diez E, Denison S, Tilburn J, Espeso E, Peñalva $M$, Arst $H$ Jr: Ambient pH signal transduction in Aspergillus: completion of gene characterization. Mol Microbiol 1999, 33:994-1003.

40. Herranz S, Rodríguez J, Bussink H, Sánchez-Ferrero J, Arst H Jr, Peñalva $\mathrm{M}$, Vincent $\mathrm{O}$ : Arrestin-related proteins mediate $\mathbf{p H}$ signaling in fungi. Proc Natl Acad Sci USA 2005, 102:12141-12146.

41. Calcagno-Pizarelli A, Negrete-Urtasun S, Denison S, Rudnicka J, Bussink H, Múnera-Huertas T, Stanton L, Hervás-Aguilar A, Espeso E, Tilburn J, Arst H Jr, Peñalva M: Establishment of the ambient pH signaling complex in Aspergillus nidulans: Pall assists plasma membrane localization of PalH. Eukaryot Cell 2007, 6:2365-2375

42. Denison S, Orejas $M$, Arst HJ: Signaling of ambient $\mathbf{p H}$ in Aspergillus involves a cysteine protease. J Biol Chem 1995, 270:28519-28522.

43. Negrete-Urtasun S, Denison S, Arst HJ: Characterization of the pH signal transduction pathway gene palA of Aspergillus nidulans and identification of possible homologs. J Bacteriol 1997, I79:1832-1835

44. Vincent $O$, Rainbow L, Tilburn J, Arst H Jr, Peñalva M: YPXL/I is a protein interaction motif recognized by Aspergillus PalA and its human homologue, AIPI/Alix. Mol Cell Biol 2003, 23:1647-1655.

45. Galindo A, Hervás-Aguilar A, Rodríguez-Galán $\mathrm{O}$, Vincent $\mathrm{O}$, Arst $\mathrm{H}$ Jr, Tilburn J, Peñalva M: PaIC, one of two Brol domain proteins in the fungal $\mathrm{pH}$ signaling pathway, localizes to cortical structures and binds Vps32. Traffic 2007, 8: I346-I364.

46. Peñas $M$, Hervás-Aguilar $A$, Múnera-Huertas $T$, Reoyo $E$, Peñalva $M$, Arst $\mathrm{H}$ Jr, Tilburn J: Further characterization of the signaling proteolysis step in the Aspergillus nidulans $\mathrm{pH}$ signal transduction pathway. Eukaryot Cell 2007, 6:960-970.

47. Merbel $\mathrm{N}$ van de, Ruijter $\mathrm{G}$, Lingeman $\mathrm{H}$, Brinkman U, Visser J: An automated monitoring system using on-line ultrafiltration and column liquid chromatography for Aspergillus niger fermentations. Appl Microbiol Biotechnol 1994, 41:658-663.

48. Pedersen H, Christensen B, Hjort C, Nielsen J: Construction and characterization of an oxalic acid nonproducing strain of Aspergillus niger. Metab Eng 2000, 2:34-41.

49. Arst $\mathrm{H}$ Jr, Peñalva $M$ : Recognizing gene regulation by ambient pH. Fungal Genet Biol 2003, 40: I-3.

50. Andersen M, Vongsangnak W, Panagiotou G, Salazar M, Lehmann L, Nielsen J: A tri-species Aspergillus micro array: comparative transcriptomics of three Aspergillus species. Proc Natl Acad Sci USA 2008, 105:4387-4392.

51. Affymetrix: GeneChip Expression Analysis Technical Manual, with Specific Protocols for Using the GeneChip Hybridization, Wash, and Stain Kit. P/N 702232 Rev. 22007.

52. R: A Language and Environment for Statistical Computing. [http://www.R-project.org]

53. Irizarry R, Hobbs B, Collin F, Beazer-Barclay $Y$, Antonellis K, Scherf $U$, Speed $T$ : Exploration, normalization, and summaries of high density oligonucleotide array probe level data. Biostatistics 2003, 4:249-264.

54. Bolstad B, Irizarry R, Åstrand M, Speed T: A comparison of normalization methods for high density oligonucleotide array data based on variance and bias. Bioinformatics 2003, 19: 185-193.

55. Gautier L, Cope L, Bolstad B, Irizarry R: affy: analysis of Affymetrix GeneChip data at the probe level. Bioinformatics 2004, 20:307-3I5.

56. Smyth G: Linear models and empirical Bayes methods for assessing differential expression in microarray experiments. Stat Appl Genet Mol Biol 2004, 3:. Article 3

57. Benjamini $Y$, Hochberg $Y$ : Controlling the false discovery rate: a practical and powerful approach to multiple testing. J Royal Stat Soc B 1995, 57:289-300.

58. Grotkjaer T, Winther O, Regenberg B, Nielsen J, Hansen L: Robust multi-scale clustering of large DNA microarray datasets with the consensus algorithm. Bioinformatics 2006, 22:58-67.

59. Bembom $O$, Keles $S$, Laan $M$ van der: Supervised detection of conserved motifs in DNA sequences with Cosmo. Stat Appl Genet Mol Biol 2007, 6:. Article 8

60. Gentleman RC, Carey VJ, Bates DM, Bolstad B, Dettling M, Dudoit S, 
Ellis B, Gautier L, Ge Y, Gentry J, Hornik K, Hothorn T, Huber W, lacus S, Irizarry R, Li FLC, Maechler M, Rossini AJ, Sawitzki G, Smith C, Smyth G, Tierney L, Yang JYH, Zhang J: Bioconductor: Open software development for computational biology and bioinformatics. Genome Biol 2004, 5:R80.

61. Alexa A, Rahnenführer J, Lengauer T: Improved scoring of functional groups from gene expression data by decorrelating GO graph structure. Bioinformatics 2006, 22:1600-1607.

\begin{tabular}{l} 
62. JGI Aspergillus niger v I.0. [http://genome.jgi-psf.org/Aspnil/ \\
\hline
\end{tabular} Aspnil.home.html]

63. Schneider T, Stephens R: Sequence logos: a new way to display consensus sequences. Nucleic Acids Res 1990, I 8:6097-6I00.

64. Tilburn J, Sánchez-Ferrero J, Reoyo E, Arst H Jr, Peñalva M: Mutational analysis of the $\mathrm{pH}$ signal transduction component $\mathrm{PaIC}$ of Aspergillus nidulans supports distant similarity to BROI domain family members. Genetics 2005, 171:393-40I. 